\title{
A Study of Environmental Awareness of Student Teachers and Teachers in Relation of Their Emotional Intelligence
}

\author{
Seema Sharma \\ Department of Education, CCS University Meerut College (UP), Meerut, India \\ Email: sssharmaccs@gmail.com
}

Received 19 June 2014; revised 31 July 2014; accepted 18 August 2014

Copyright (C) 2014 by author and Scientific Research Publishing Inc.

This work is licensed under the Creative Commons Attribution International License (CC BY). http://creativecommons.org/licenses/by/4.0/

cC) (i) Open Access

\section{Abstract}

The study aimed at finding out the relationship between environmental awareness and emotional intelligence of student teachers and teachers. The sample of the study consisted of 200 student teachers (100 male and 100 female) and also of 100 teachers (50 male and 50 female). The sample was taken from 15 self-financed B.Ed. colleges of Ghaziabad District of CCS University, Meerut (UP). Environmental awareness measure scale by Dr. P. K. Jha and emotional intelligence inventory by Dr. S. K. Mangal and Mrs. Shubhra Mangal was used for assessing the environmental awareness and emotional intelligence of student teachers and teachers. Data was analyzed by using mean, SD, t-test and by Pearson Product Moment Correlation Technique. The results showed that there was no significant difference between male and female student teachers and teachers regarding environmental awareness and emotional intelligence. The results also showed that the environmental awareness of male and female student teachers was also found to be slightly positively but not significantly correlated with emotional intelligence. The environmental awareness of male teachers was found to be moderately, positively and significantly correlated with emotional intelligence. on the other hand the environmental awareness of female teachers was found to be slightly positively but not significantly correlated with emotional intelligence.

\section{Keywords}

Management Skills, Regularity, Emotional Intelligence

\section{Introduction}

We have entered in the $21^{\text {st }}$ century, an era of science and technology. Man has made his life much more com- 
fortable than ever before. While doing so, he has destroyed forests, polluted air, water and disturbed natures balance. The rate of extinction of species of animals and plants has been rising. Now the question comes before us, how to stop this extinction of species? The obvious answer is Environmental Awareness. We can save our species only when we organize Environmental Awareness Programmes on a large scale. The Government and various Non-Government Organizations can adopt different-different strategies to promote awareness on environment in the country. The ministry of Environment and Forests can accord top priority to promote environmental awareness among various age groups. The National Museum of National History, New Delhi may promote non-formal education in the area of environment and conservation. Non-Government Organizations also play a critical and crucial role in advancing environmental awareness through research, publications, training and other activities. Organizations like the National Council for Educational Research and Training also play a crucial role in promoting environmental awareness. Environmental awareness being so important, it is expected that the teachers should make the students socially aware of the need for environmental preservation. The purpose of environmental awareness is to improve the quality of environment and create awareness among the people on environmental problems and conservation. World's educators and environment specialists have repeatedly pointed out that any solution to the environmental crisis will require environmental awareness and understanding to be deeply rooted in the educational system at all levels.

Emotional intelligence plays a very important role in raising [1] environmental awareness among all individuals in the society. In fact emotional intelligence is defined as emotional awareness and emotional management skill which provide the ability to balance emotion and reason so as to maximize productivity and happiness. Therefore, a proper management of emotional intelligence is necessary for all students and teachers to get rid from all environment related problems [2]. Emotionally balanced students and teachers can only develop a wave of awareness among the people towards environment. They can aware the society that all the resources of environment are exhaustable and if we will not use these resources properly we are going to face many troubles in future. They can aware the society that their polluting activities are only damaging our environment and to have a healthy environment they must stop those activities which causes degradation to environment [3]. Moreover, emotionally balanced students and teachers can only develop a sense of awareness towards environment among people. They can inspire them to use more and more artificial or man-made resources instead of natural resources. Finally, emotionally intelligent students and teachers can encourage people to use recyclable materials and to conserve energy for future demands. To make society environmentally awared, emotionally balanced students and teachers can arrange different-different seminars, lectures, parents-teachers meetings and etc in schools and college [4] [5]. In these meetings they can change the emotions, behaviours, actions of people and can try to literate the society towards environment.

\subsection{The Study Aims}

1) To study and compare the environmental awareness of male and female student teachers and male and female teachers. To study the environmental awareness of male and female teachers.

2) To study and compare the emotional intelligence of male and female student teachers, and male and female teachers.

3) To study the relationship between the environmental awareness and emotional intelligence of male and female student teachers and male and female teachers.

\subsection{Research Questions}

1) Is there any significant difference between the environmental awareness of male and female student teachers and male and female teachers?

2) Is there any significant difference between the emotional intelligence of male and female student teachers and male and female teachers?

3) Is there any significant relationship between the environmental awareness and emotional intelligence of male and female student teachers and male and female teachers?

\section{Methodology}

The present study is related to the student teachers and teachers of self-financed B.Ed. colleges of Ghaziabad 
District. Hence, the investigator selected a sample of 200 student teachers out of which 100 male and 100 female student teacher's have been taken \& also a sample of 100 teachers' out of which 50 male and 50 female teachers have been taken from self-financed B.Ed. colleges of Ghaziabad District. According to the need and conditions of the problem - "Stratified Random Sampling Technique" is used by the investigator.

An authenticity of the study depends upon the selection of appropriate tools with the help of which data is collected. Since the study principally contains two variables namely-Environmental Awareness and Emotional Intelligence therefore it was decided by the investigator that he should choose those tools which are reliable and valid. Hence, after a great consideration following tools were selected by the investigator:

1) Environment Awareness Ability Measure Scale: To study the environment awareness of student teachers and teachers, environment awareness ability measure scale by Dr. Praveen Kumar Jha is used by the investigator.

2) Emotional Intelligence Inventory: To study the emotional intelligence of student teachers and teachers, Mangal emotional intelligence inventory by Dr. S. K. Mangal and Mrs. Shubhra Mangal is used by the investigator.

After establishing a proper rapport with the student teachers and teachers of self financed B.Ed. colleges of Ghaziabad district the Environment Awareness Ability Measure Scale and the Emotional Intelligence Inventory were administered. In order to collect the relevant data for both the scales the investigator himself visited different-different self-financed B.Ed. colleges and many other places of Ghaziabad District. The above mentioned procedure was followed for the collection of relevant data.

\section{Results and Discussion}

The data collected by means of questionnaire was analyzed. The analysis was done by using mean, SD, t-test and by using Pearson's Product Moment Technique. The whole description of analysis is given below:

1) To study the difference between the environmental awareness of male and female student teachers, the scores obtained from both the groups were tabulated for comparing mean and S.D. After obtaining the mean and S.D., the t-test was applied. The table of analysis is given below.

Table 1 reveals that the computed value of $t$ is 0.4 . The critical value of $t$ with 198 degrees of freedom and at $5 \%$ level of significance is 1.97 . Our computed value of $t$ is 0.4 which is quite smaller than the critical table value 1.97, even at $5 \%$ level of significance and hence is not significant. Therefore, the null hypothesis cannot be rejected and as a result. The given difference in sample means being insignificant can only be attributed to some chance factors or sampling fluctuations.

2) To study the difference between the environmental awareness of male and female teachers, the scores obtained from both the groups were tabulated for comparing mean and SD. After obtaining the mean and SD, the t-test was applied. The table of analysis is given below.

Table 2 reveals that the computed value of $t$ is 0.53 . The critical value of $t$ with 98 degrees of freedom and at $5 \%$ level of significance is 1.98 . Our computed value of $t$ is 0.53 which is quite smaller than the critical table value 1.98, even at $5 \%$ level of significance and hence is not significant. Therefore the null hypothesis cannot be rejected and as a result. The given difference in sample means being insignificant can only be attributed to some chance factors or sampling fluctuations.

Table 1. Overview analysis of male and female student teachers showing computed value of $\mathrm{t}$ as 0.4 .

\begin{tabular}{cccccccr}
\hline Group & N & Mean & S.D. & SE $_{\mathbf{D}}$ & t-value & df & Level of Significance \\
\hline Male St's Tr's & 100 & 43.1 & 4.86 & & & & 198 \\
Female St's Tr's & 100 & 43.34 & 3.75 & 0.06 & 0.4 & & 1.97 \\
\hline
\end{tabular}

Table 2. Overview analysis of male and female teachers showing computed value of $\mathrm{t}$ as 0.53 .

\begin{tabular}{ccccccc}
\hline Group & N & Mean & S.D. & SE $_{\mathbf{D}}$ & t-value & Level of Significance \\
\hline Male Teachers & 50 & 44.06 & 3.36 & & 0.67 & 98 \\
Female Teachers & 50 & 44.42 & 3.44 & & & \\
\hline
\end{tabular}


3) To study the difference between the emotional intelligence of male and female student teachers, the scores obtained from both the groups were tabulated for comparing mean and SD. After obtaining the mean and SD, the t-test was applied. The table of analysis is given below.

Table 3 reveals that the computed value of $t$ is 1.26. The critical value of $t$ with 198 degree's of freedom and at $5 \%$ level of significance is 1.97 . Our computed value of $t$ is 1.26 which is quite smaller than the critical table value 1.97 , even at $5 \%$ level of significance and hence is not significant. Therefore the null hypothesis cannot be rejected and as a result. The given difference in sample means being insignificant can only be attributed to some chance factors or sampling fluctuations.

4) To study the difference between the emotional intelligence of male and female teachers, the scores obtained from both the groups were tabulated for comparing mean and SD. After obtaining the mean and SD, the t-test was applied. The table of analysis is given below.

Table 4 reveals that the computed value of $t$ is 0.27 . The critical value of $t$ with 98 degrees of freedom and at $5 \%$ level of significance is 1.98 . Our computed value of $t$ is 0.27 which is smaller than the critical table value 1.98 even at $5 \%$ level of significance and hence it is not significant. Therefore the null hypothesis cannot be rejected and as a result. The given difference in sample means being insignificant can only be attributed to some chance factors or sampling fluctuations.

5a) To study the relationship between the environmental awareness and emotional intelligence of male student teachers pearsons product moment technique was applied between the scores of male student teachers in both the variables. The table of analysis is given below.

Table 5(a) reveals that the coefficient of correlation between the environmental awareness and emotional intelligence of male student teachers is 0.098 , which is slightly positive and with 98 degrees of freedom it is not significant, even at 0.05 level of significance so the null hypothesis cannot be rejected. Thus, it can be interpreted that there is no significant relationship between the environmental awareness and emotional intelligence of male student teachers.

5b) To study the relationship between the environmental awareness and emotional intelligence of female student teachers Pearson's Product moment technique was applied between the scores of female student teachers in both the variables. The table of analysis is given below.

Table 5(b) reveals that the coefficient of correlation between the environmental awareness and emotional intelligence of female student teachers is 0.097 , which is slightly positive and with 98 degrees of freedom it is

Table 3. Overview analysis of male and female student teachers showing computed value of $\mathrm{t}$ as 1.26.

\begin{tabular}{cccccccr}
\hline Group & $\mathbf{N}$ & Mean & S.D. & SE $_{\mathbf{D}}$ & t-value & df & Level of Significance \\
\hline Male St's Tr's & 100 & 71.74 & 10.5 & \multirow{2}{*}{1.38} & 1.26 & 198 & 1.97 \\
Female St's Tr's & 100 & 70 & 9.06 & & & & \\
\hline
\end{tabular}

Table 4. Overview analysis of male and female teachers. showing computed value of $t$ as 0.27 .

\begin{tabular}{cccccccc}
\hline Group & N & Mean & S.D. & SE $_{\mathbf{D}}$ & t-value & df & Level of Significance \\
\hline Male Teachers & 50 & 70.7 & 12.5 & 2.2 & \multirow{2}{*}{0.27} & \multirow{2}{*}{98} & 1.98 \\
Female Teachers & 50 & 71.3 & 9.3 & & & & \\
\hline
\end{tabular}

Table 5. (a) Overview coefficient correlation between environmental awareness and emotional intelligence of male student teachers; (b) Overview coefficient correlation between environmental awareness and emotional intelligence of female student teachers.

(a)

\begin{tabular}{cccccr}
\hline Group & $\mathbf{N}$ & Variables & R & df & Level of Significance \\
\hline Male St's Tr's & 100 & $\begin{array}{c}\text { Environmental Awareness } \\
\text { Emotional Intelligence }\end{array}$ & 0.098 & 98 & 0.195 \\
\hline
\end{tabular}

(b)

\begin{tabular}{cccccr}
\hline Group & N & Variables & R & df & Level of Significance \\
\hline Female St's Tr's & 100 & $\begin{array}{c}\text { Environmental Awareness } \\
\text { Emotional Intelligence }\end{array}$ & 0.097 & 98 & 0.195 \\
\hline
\end{tabular}


not significant, even at 0.05 level of significance so the null hypothesis cannot be rejected. Thus, it can be interpretated that there is no significant relationship between the environmental awareness and emotional intelligence of female student teachers.

6a) To study the relationship between the environmental awareness and emotional intelligence of male teachers pearsons product moment technique was applied between the scores of male teachers in both the variables. The table of analysis is given below.

Table 6(a) reveals that the coefficient of correlation between the environmental awareness and emotional intelligence of male teachers is 0.449 , which is moderately positive and with 48 degrees of freedom it is significant, even at 0.05 and 0.01 level of significance so the null hypothesis is rejected. Thus, it can be interpretated that there is significant relationship between the environmental awareness and emotional intelligence of male teachers.

6b) To study the relationship between the environmental awareness and emotional intelligence of female teachers again pearson's product moment technique was applied between the scores of female teachers in both the variables. The table of analysis is given below.

Table 6(b) reveals that the coefficient of correlation between the environmental awareness and emotional intelligence of female teachers is 0.18 , which slightly positive and with 48 degrees of freedom it is not significant, even at 0.05 level of significance so the null hypothesis cannot be rejected. Thus, it can be interpretated that there is no significant relationship between environmental awareness and emotional intelligence of female teachers.

\section{Conclusions}

Following inferences were drawn on the basis of findings:

1) No significant difference was observed between male and female student teachers regarding environmental awareness.

2) Similarly no significant difference was observed between male and female teachers regarding environmental awareness.

It can be concluded that both male and female student teachers and teachers are environmentally awared. Both of them know that environmental awareness provides a sense of vision to understand the interrelations and interaction between the living system and life. Moreover, both of them have a strong feeling that environmental awareness provides power and understanding to take decisions individually and collectively and initiate actions for social, cultural and economic survival, growth and development and for conservation of nature and natural resources.

3) No significant difference was observed between male and female student teachers regarding emotional intelligence.

4) Similarly no significant difference was observed between male and female teachers regarding emotional intelligence.

It can be concluded that both male and female student teachers and teachers are emotionally intelligent. Both of them are having in themselves the deep roots of the five elements of emotional intelligence as-self-awareness, self-regulation, motivation, empathy and social skills. Both of them know how their feelings and emotions will affect their as well as other performance. Moreover, they know their personal strength and weaknesses and show interest for self-development.

Table 6. (a) Overview coefficient correlation between environmental awareness and emotional intelligence of male teachers; (b) Overview coefficient correlation between environmental awareness and emotional intelligence of female teachers.

(a)

\begin{tabular}{cccccc}
\hline Group & N & Variables & r & df & Level of Significance \\
\hline Male Teachers & 50 & $\begin{array}{c}\text { Environmental Awareness } \\
\text { Emotional Intelligence }\end{array}$ & 0.449 & 48 & 0.273 at 0.05 \\
& & & 48.354 at 0.01 \\
\hline
\end{tabular}

(b)

\begin{tabular}{cccccc}
\hline Group & N & Variables & r & df & Level of Significance \\
\hline Female Teachers & 50 & $\begin{array}{c}\text { Environmental Awareness } \\
\text { Emotional Intelligence }\end{array}$ & 0.18 & 48 & 0.273 \\
\hline
\end{tabular}


5) No significant relationship was observed between the environmental awareness and emotional intelligence of male student teachers. Similarly there exists no significant relationship between the environmental awareness and emotional intelligence of female student teachers. Thus, it can be concluded that emotional intelligence is not one of the reason which influences environmental awareness in both, male and female student teachers.

6) A significant relationship was observed between the environmental awareness and emotional intelligence of male teachers. Thus it can be said that in the case of male teachers both variables are proportionally correlated with each other. Change in emotional intelligence is directly proportional to environmental awareness. On the other hand, no significant relationship was observed between the environmental awareness and emotional intelligence of female teachers. Thus, it can be concluded that emotional intelligence is not one of the reasons which influences environmental awareness in female teachers.

\section{References}

[1] Aunkumar, J. (2012) A Study on Assessment of Environmental Awareness among Teacher Trainees in Teacher Training Institutes. International Journal of Research in Social Sciences, 3, 312-321.

[2] Akers, C., Miller, K., Fraze, S.D. and Haygood, J.D. (2004) A Tri-State Needs Assessment of Emotional Intelligence in Agricultural Education. Journal of Agricultural Education, 45, 86-94. http://dx.doi.org/10.5032/jae.2004.01086

[3] D’ Zurilla, T.J. (1998) Handbook of Cognitive Behavioural Therapies. The Guilford Press, New York.

[4] Krishnamurthi, R. and Ganesan, S. (2008) Reception of Emotional Intelligence Training by Management Students. ICFAI Journal of Organizational Behaviour.

[5] Sahnawaj (1990) Environmental Awareness and Environmental Attitude of Secondary and Higher Secondary School Teachers and Students. Ph.D., Edu., University of Rajasthan, Jaipur. 
Scientific Research Publishing (SCIRP) is one of the largest Open Access journal publishers. It is currently publishing more than 200 open access, online, peer-reviewed journals covering a wide range of academic disciplines. SCIRP serves the worldwide academic communities and contributes to the progress and application of science with its publication.

Other selected journals from SCIRP are listed as below. Submit your manuscript to us via either submit@scirp.org or Online Submission Portal.
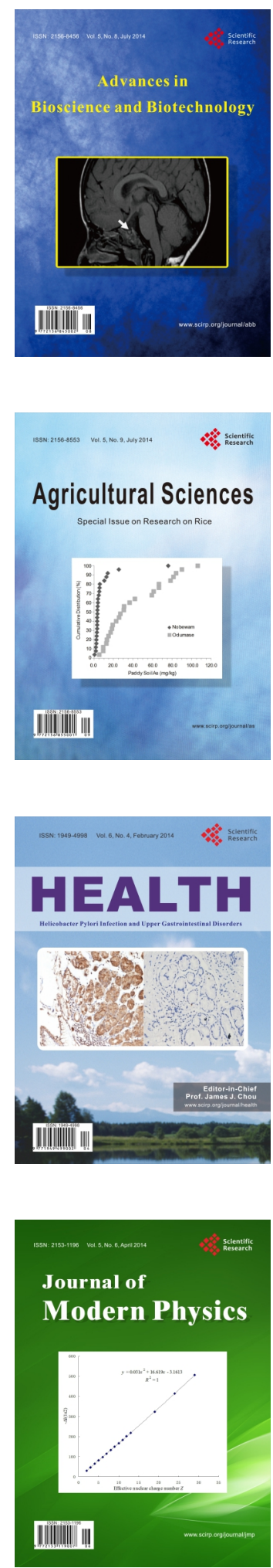
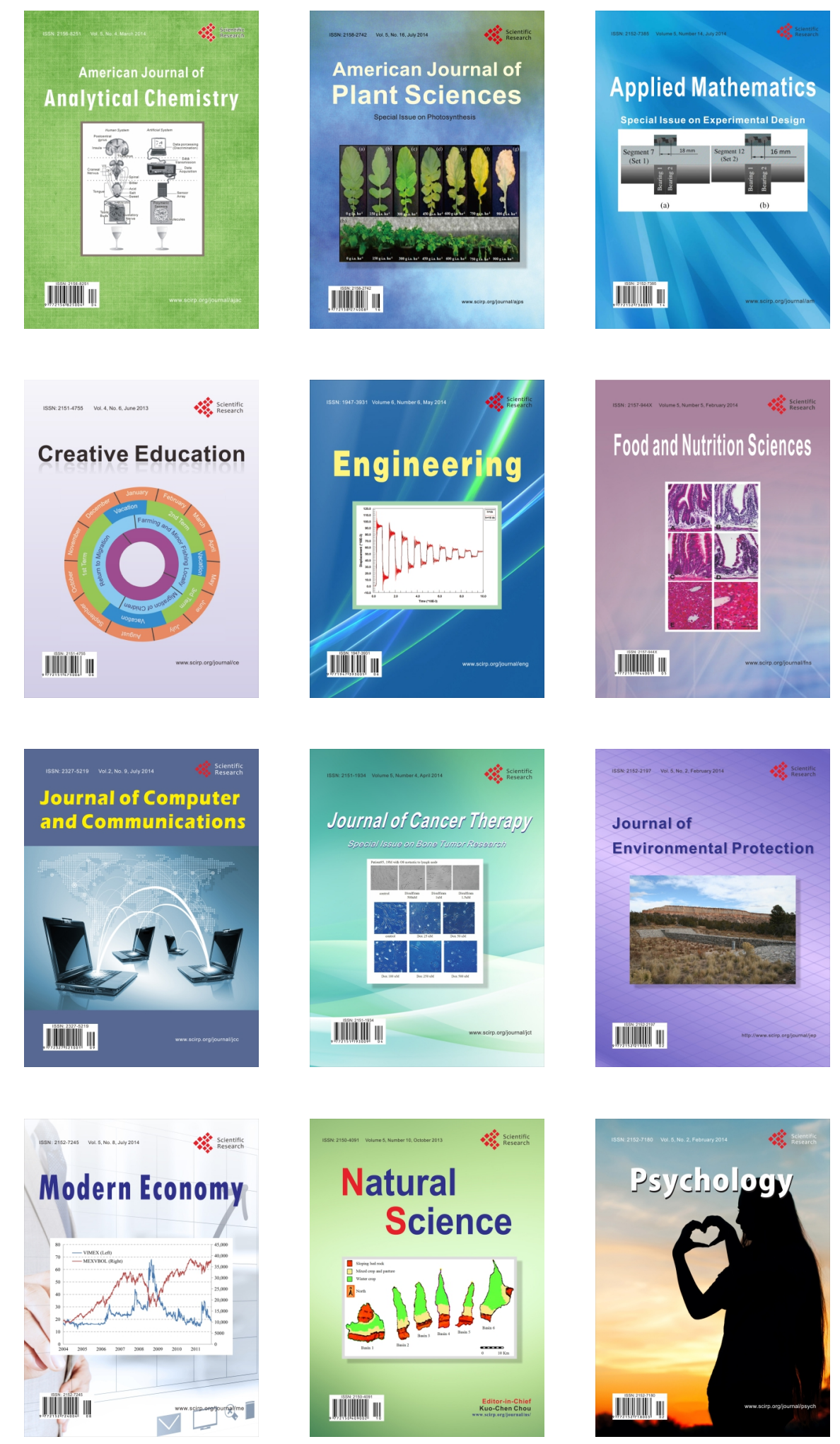